\title{
Educação teatral como produção de subjetividade.
}

\section{Theater education as subjectivity production.}

\author{
André Luiz Lopes Magela \\ Universidade Federal de São João del-Rei | São João del-Rei, MG, Brasil. \\ andremagela@ufsj.edu.br | ORCID: https://orcid.org/0000-0002-0574-0599 \\ DOI: $10.20396 /$ conce.v8i2.8656489. \\ Submetido em: 01/09/2019 | Aceito em: 24/10/2019 | Publicado em: 20/12/2019.
}

0000000000000000000000000000000000000000000000000000000000000000000000000000000000000000000000000000

\section{Resumo}

Este artigo visa a caracterizar situações em que aulas de teatro possam fomentar uma produção de subjetividade potente, singular, junto a seus alunos. Como exemplo, será analisado um exercício realizado em uma aula de teatro dentrodeumprocessodepesquisa,propondoqueelementos ali ocorridos se deram de modo análogo (homônomo) aos de processos de subjetivação. As referências são conceitos de Gilles Deleuze, Félix Guattari e Michel Foucault.

\begin{abstract}
This article aims to identify situations in which theater classes can foster a potent and singular production of subjectivity with their students. As an example, an exercise performed in a theater class within a research process will be analyzed, proposing that elements which happened there were analogous ("homonomous") to those of subjectivation processes. The references used are concepts by Gilles Deleuze, Félix Guattari and Michel Foucault.
\end{abstract}

PALAVRAS-CHAVE

Educação

Teatral.

Produção de Subjetividade. Processos de Subjetivação.
KEYWORDS Theater Education. Subjectivity Production.

Subjectivation Process. 


\section{Como fazer um "como"}

Jacques Rancière, em uma conferência sobre relações entre arte e resistência política, foi claro em desqualificar qualquer ilusão de haver uma superioridade ética dos artistas em relação às outras pessoas, ao afirmar que "sabemos que os artistas não são nem mais nem menos rebeldes que as demais categorias da população" (2007, p. 127). Dentre outras implicações, esta frase indica reservas quanto a promessas de aprimoramento ético presentes em ma-nifestações artísticas e em suas educações, e nos convoca a investigar como classes de teatro poderiam realmente contribuir com melhorias da vida, "não pelo acúmulo de bens materiais, mas pela constituição de valores eticamente aceitos por uma determinada comunidade" (ICLE, 2010, p. 23).

A importância e a justificativa para o ensino de artes na formação dos cidadãos ainda estão em terreno epistemológico excessivamente vago. Com algumas exceções históricas, como o Projeto Zero1, iniciado na universidade de Harvard em 1967, virtualmente não há pesquisas de longo prazo sobre o ensino de artes que possam contribuir para definir de maneira mais generalizante e com clareza as referências para esta área de pensamento pedagógico.

(...) em uma perspectiva de justificação, avaliação e legitimação da educação artística, as pesquisas realizadas até o momento permanecem insuficientes, não fornecendo um método confiável ou modelo explicativo generalizável para entender o que está em jogo nesta formação holística do sujeito através da arte2. (CHOQUET \& KERLAN, 2016, p. 5.)

Temos poucas respostas sobre os efeitos da educação artística sobre seus alunos no que tange à contribuição para as suas vidas. E mesmo os termos das questões e critérios de avaliação relativos a isto estão longe de ser bem colocados. As pesquisas ainda elegem critérios vagos e exógenos (extrínsecos) às artes para avaliar seus efeitos pedagógicos, atendo-se a considerar, por exemplo, a desenvoltura relacional e o desempenho acadêmico melhorado (CHOQUET \& KERLAN, 2016), ou se restringem demais na avaliação da influência de au-las de artes sobre a performance dos alunos em matemática e línguas (OCDE, 2013). 
Esta obra recente da OCDE, "L'Art pour l'art" (2013), apesar de suas limi-tações quanto a não reconhecer a importância dos aspectos estéticos de modo intrínseco (BORDEAUX, 2016, p. 14) e no cotidiano da vida de todos, ao mes-mo tempo traz a ideia importante de que a maneira como se conduz uma aula de artes é que pode, ou não, trazer resultados interessantes para os alunos, mesmo que os mecanismos não estejam ainda nada esclarecidos. Dizendo de outro modo, e em acordo com a fala de Rancière, não é qualquer aula de artes (no nosso caso aqui, de teatro) que pode fomentar uma expansão pertinente da percepção de seus alunos, principalmente se considerarmos elementos éticos nesta avaliação.

No Brasil, mesmo com a significativa conquista, graças aos movimentos que tiveram seu ápice na década de 1990 (SANTANA, 2009), de que o ensino de teatro seja realizado por professores especializados em universidades ou similares, ainda há também precariedades quanto aos referenciais pedagógicos oferecidos e utilizados por estes docentes. Além disso, é internacionalmente admitido que as justificativas, para toda a sociedade, de o porquê haver aulas de artes, inclusive de teatro, para todas as crianças e todos os jovens, estão longe de ter convencido as instâncias decisórias em educação - sendo o Brasil atual um paroxismo deste problema.

Uma linha argumentativa apresentada aqui é sugerir que estas aulas toquem o que é político, efetivamente ético na vida de seus alunos, ao remeter aos processos mais importantes de suas vidas: a sobrevivência, por exemplo - e de preferência influenciá-los de modo positivo. É um utilitarismo peculiar, uma vez que considera a arte como essencial para a vida. Nesta linha, é preciso tecer um quadro de compreensão e de direcionamento das aulas de teatro em escolas que as tornem instrumentais ( aluno, principalmente em seu comportamento, em suas decisões, nos aspectos ético-estéticos de seu cotidiano.

Estes processos estariam relacionados às formas de pensamento teatral já tratadas em artigo anterior (MAGELA, 2018): a teatralidade imbricada à vida. Trata-se, por exemplo, do planejamento e compreensão de eventos e a percep-ção mais complexa do espaço, do tempo e de relações humanas ou a capacida-de de invenção colaborativa de outros mundos de experiência e novas formas de viver. A aposta é que o setting da aula de teatro intensifique a atenção conec-tada a estas dimensões teatrais da vida, superando o automatismo que apenas 
resolve problemas e tarefas e compondo qualidades de atenção para relações mais inventivas. Esta realidade teatral seria um dos grandes campos que estas aulas abordariam: um estrato teatral que forma a vida cotidiana e que a prática da cena pedagogicamente qualificada exercita e amplia.

Este artigo enfocará um possível modo de aulas de teatro atuarem de forma significativa no jeito como seus participantes lidam com a teatralidade da vida. De maneira bastante sintética, o que será exposto é que, se consideramos que forças e formas teatrais estão presentes no cotidiano, elas correspondem a processos de subjetivação. Assim, se as aulas podem propor experiências imersivas em articulações destas formas e forças teatrais, elas podem processar subjetivação, produzir subjetividade, modos de vida teatrais em aula que podem transbordar, somaticamente (MAGELA, 2017) para a vida dos alunos.

\section{Estudos da subjetividade e docência de teatro}

Para expor melhor o que será abordado nas reflexões sobre a produção de subjetividade, é preciso antes esclarecer o que consideramos como processo de subjetivação:

(...) não perguntar porque alguns querem dominar, o que procuram e qual é sua estratégia global, mas como funcionam as coisas ao nível do processo de sujeição ou dos processos contínuos e ininterruptos que sujeitam os corpos, dirigem os gestos, regem os comportamentos, etc. (...). Captar a instância material da sujeição enquan-to constituição dos sujeitos. (...) ... Em vez de formular o problema da alma central, creio que seria preciso procurar estudar os corpos periféricos e múltiplos, os corpos constituídos como sujeitos pelos efeitos de poder. (FOUCAULT, 1985, p. 182-183.)

Valendo-nos de Judith Revel, comentadora e estudiosa da obra de Fou-cault, vemos que os processos de subjetivação, dentro do campo conceitual foucaultiano, são ligados a modos de objetivação que constituem os seres humanos como sujeitos, "processos pelos quais obtém-se a constituição de um sujeito, ou mais exatamente de uma subjetividade" (REVEL, 2008, p. 128). Percebemos que o processo de subjetivação se imbrica com um processo de sujeição, uma das ambiguidades e contradições que caracterizam as relações de po-der. Ao mesmo tempo, com o amparo dos estudos da subjetividade, podemos tentar articular o caráter "assujeitador" dos processos de subjetivação com uma desejável singularização presente em produções criativas de subjetividade.

Se estes processos são importantes na vida, constitutivos de nossos mo- 
dos de ser e de nossa experiência, é essencial que haja aulas que toquem estas operações que fazemos na vida. O que queremos mostrar aqui é que ao falar de subjetivação, percebemos haver uma homonomia, uma analogia em modos de operar, entre o teatro e a vida, nos modos de operação do poder. Se pers-pectivamos a teatralidade presente na vida como uma articulação complexa de formas e forças que modulam o tempo, o espaço e o comportamento (um processo de subjetivação), talvez possamos em aulas de teatro abordar o modo como alunos produzem subjetividade, como eles percebem as forças e formas da aula e da vida e produzem modos potentes de se relacionar com isto. Isto definiria as aulas de teatro e as tornaria menos dependentes da cultura de pro-fissionalização de atores.

As abordagens que enxergam o aluno como aquele que deve se submeter à "alfabetização do indivíduo na linguagem da cena produzida por profissionais” (ANDRÉ, 2008, p. 134) não se distanciam das práticas em que o aluno deve se tornar um "capital humano", que será aproveitado nos sistemas profissionais ou econômicos, no mercado de trabalho do teatro ou outros mercados, onde se espera que ele tenha desenvolvidas "competências" ou "criatividade" (elementos caros à educação formadora de mão de obra) (COSTA, 2009). Desse modo, a educação funciona como um dispositivo, como "investimento cuja acumulação permitiria não só o aumento da produtividade do indivíduo-trabalhador, mas também a maximização crescente de seus rendimentos ao longo da vida" (GADELHA3, 2009, p. 150). A educação, neste enfoque, se relacionaria aos processos de subjetivação quanto à "produção de sujeitos":

(...) em se tratando da educação, poder-se-ia falar dos modos através dos quais ela se agencia à questão ou ao problema 'da subjetividade': num primeiro caso, envolvendo-se em pro-cessos, políticas, dispositivos e mecanismos de subjetivação, isto é, de constituição de iden-tidades, de personalidades, de formas de sensibilidade, de maneiras de agir, sentir e pen-sar, normalizadas, sujeitadas, regulamentadas, controladas... (GADELHA, 2009, p. 173.)

E com isto, pela produção positiva de formas específicas de relação, minar os "mecanismos sociais que favorecem ou autorizam a experiência comum da vida como unidade e como totalidade" (BOURDIEU, 2006, p. 185):

O mundo social, que tende a identificar a normalidade com a identidade en-tendida como constância em si mesmo de um ser responsável, isto é, previ-sível ou, no mínimo, inteligível, à maneira de uma história bem construí-da (por oposição à história contada por um idiota), dispõe de todo tipo de instituições de totalização e de unificação do eu. (BOURDIEU, 2006, p. 186.) 
O que nos interessa aqui é a criação de condições para a produção singu-lar de subjetividade. O ensino de teatro em escolas, deste modo, foge à norma-lização e visa a produzir formas inventivas e estratégicas de viver:

(...) num segundo caso, em que a resistência ao poder entra em foco, dando-se por uma via ético-estética, pode-se pensar como ela, a educação, se encontra implicada na inven-ção de maneiras singulares de relação a si e com a alteridade. (GADELHA, 2009, p. 173.)

A docência de teatro se valeria dos aspectos pedagógicos da artesania na-quilo que mobiliza, amplia, a atenção dos alunos. Esta produção de subjetivi-dade ocorreria conectada a um pensamento teatral, a uma inteligência presente na percepção daquilo que é teatral no acontecimento. Das muitas inteligências ativadas na percepção, caberia a nós, professores de teatro, que desejamos e devemos influenciar a vida de todos os brasileiros, dirigir nossa docência ao pensamento teatral.

\section{Forças, poder, subjetivação}

Se retomamos, como objetivo da educação teatral, estabelecer a conexão daquilo que se faz em uma aula de teatro com aquilo que compõe teatralmente a vida cotidiana, uma filosofia vitalista (que concerne aos fluxos da vida) pode ser conectada às atividades de educação teatral (MAGELA, 2019b) (MAGELA, 2017b)4. Assim, esta conexão já é uma viabilização, ao menos teórica ou atitu-dinal, da transposição das aulas para a vida. Neste aspecto é que se configura a imbricação da experiência da aula de teatro com processos de subjetivação, estudos da subjetividade e filosofias da diferença.

Minha especialização é em educação teatral, mas também ministro disciplinas ligadas à atuação (que é o meu foco na licenciatura). Durante minhas pesquisas sobre a associação entre aulas de teatro e produção de subjetividades, houve um encontro em uma disciplina específica de improvisação, em que havia poucos alunos, todos licenciandos que já tinham alguma experiência de atuação e de docência em teatro.

No meio desse semestre, já tendo sido construído um processo pedagógico entre nós, os alunos trabalharam uma improvisação "livre", que pode ser comparada a um parateatro ou dinâmica dramática. Antes desse dia de aula, 
houve um intervalo de tempo de trabalho, causado por um dia de ausência minha e duas semanas acadêmicas, que interromperam o trabalho intenso do início do semestre.

No dia analisado, os alunos chegaram e, sem falar nada, sem conversar (ética previamente estabelecida), fizemos uma roda (eu conduzi isso). Cantei algumas músicas, tentando induzir que cantassem também, sem sucesso (admito que minha intervenção foi "clichetípica"). Eles não aderiram e eu fiquei cantando sozinho um pouco, menos de uma música (voz e música não são meu foco e de fato são uma deficiência em meu trabalho). Mas este insucesso não causou problemas para o ambiente de trabalho. Ficamos em silêncio um tempo, de mãos dadas. Eu saí da roda e apaguei as luzes, deixando-os neste va-zio (havia iluminação difusa e fraca vinda das janelas). Eles começaram a fazer coisas, mas notei que, desde o início, não caíram na necessidade de preenchi-mento - eles estavam tranquilos e sem propor comportamentos conhecidos ou recursos prévios de atuação.

É preciso notar que isso só foi proposto porque tínhamos um trabalho anterior e, no dia, percebi uma oportunidade para tentar esse início de aula mais "estético" (uma "aula-acontecimento" que eu inclusive desejava nesse mo-mento do processo). E o mais importante na minha avaliação dessa aula foi perceber que, nessa improvisação inicial deles, havia uma instância que talvez possa ser chamada de "pré-jogo", em que eles não tentavam interagir dentro de padrões de responsividade social, de interação, de comunicação, até de jogo talvez. Essa percepção era então nova nesse processo.

O trabalho foi interrompido por mim para resolver um problema de segu-rança (um pedaço de metal que poderia feri-los) e, após isto, ao retornarem, a instância específica havia se perdido totalmente. Eles começaram a improvisar, jogar, etc., normalmente, dentro de padrões de interação mais reconhecíveis. Interrompi isso e fomos para um dia de trabalho normal, com aquecimentos e improvisações.

Refletindo sobre o que ocorreu, pensei que aquela instância de "pré-jogo" identificada era caracterizada por um modo específico de relações de forças, de influências mútuas que construíam o que se passava e o que "eram" as pessoas que estavam construindo(-se) a situação. As pessoas eram as relações: 
O si e o mundo são coengendrados pela ação, de modo recíproco e indissociável. (...) Os processos de subjetivação e de objetivação fazem-se num plano aquém das formas, plano de forças moventes que, por seu agenciamento, vêm a configurar for-mas sempre precárias e passíveis de transformação. (KASTRUP, 2005a, p. 1276.)

Naquela situação, ocorrida naquele dia de aula, estavam precisamente operando, como forças, os elementos ou instâncias de percepção, ou cognitivos, abordados no início deste artigo. Este trabalho e as percepções e reflexões decorrentes abriram o caminho para que se mostrasse mais palpável, pelo menos para os presentes (e no próximo exemplo isto ficará talvez mais explícito para o leitor), a proposta de uma cognição teatral - uma forma de perceber e fazer o real que se dá teatralmente, em minimalismos e campos de percepção que não se ancoram majoritariamente na comunicação e no jogo como previamente estabelecidos, como recursos operacionais hegemônicos de relação.

Essa instância de "pré-jogo" ou "infrajogo", que surgiu no dia de trabalho, mostrou-se constituída por processos de percepção coletiva que prescindiam de uma comunicação explícita ou de um jogo mais estruturado. As ações se dão por construtos mínimos e simples, por células operativas tão elementares quanto efetivas e poderosas, forças e formas que entram na constituição de uma situação ou dimensão teatral.

Essa lógica da atividade engajada concretamente desdobrou-se, na semana seguinte, no exercício de se realizar um percurso em diagonal pela sala, com todos carregando um dos atuantes. O trabalho, de acordo com a instrução que propus, teria de ser feito sem falas, sem trocas de olhares, sem trocas de sinais - sem comunicação intencional. Outras instruções eram a de não parar e absorver as minhas instruções sem interromper o trabalho nem olhar para mim, como se estivessem trabalhando com quarta parede6, numa ética de cena convencional.

No começo do trabalho, como regra inicial, falei para que fizessem um ciclo, em que todos iam sendo levados, um por vez. Após terem sido carregados, repetiriam o carregamento de todos, mas não necessariamente na mesma ordem. Fariam tudo ininterruptamente até eu instruir a parada.

Depois de um tempo, percebi que este ciclo gerava uma racionalização 
excessiva, um ruído; que isto tomava-os de uma maneira indesejável: eles pre-cisavam se lembrar de quem foi e não foi carregado naquele ciclo, muito racio-nalmente, nos momentos de decidir quem carregar. Assim, eu sugeri, durante a prática e sem que eles parassem, que deveriam definir pelo fluxo de trabalho quem seria carregado a cada momento e como esta pessoa seria levantada e carregada, sem problemas, desde que as regras fossem acatadas, quanto aos resultados ou se alguém ficaria sem ser carregado muito tempo. De fato, deci-dir o que fazer coletivamente no fluxo das ações é tudo o que importava neste trabalho (e na vida...).

Após muitas idas e vindas (mais de trinta vezes), eles foram entrando em uma entrega e ritmo muito intensos e realmente constituindo uma instância teatral com a execução daquela tarefa dentro das instruções situadoras. Eles estavam engajados na tarefa, sem clichês de atuação, assumindo a situação e decidindo, produzindo, fazendo o que se afigurava. A inteligência de perceber, fazer, decidir, produzir cada momento sem comunicação explícita e sem cair em definições estratificadas de comportamento ou significados das ações era o mais significativo.

A criatividade dos modos de carregar não era importante (modos inusitados ou diferentes do comum, num regime de avaliação mais ligado a um pro-duto estético ou à minha fruição como observador), mas sim como eles agiam a cada segundo, a qualidade de cada decisão, a maneira como eram constitu-ídos pela interconexão coletiva, num pensamento corporal totalmente imbri-cado coletivamente com todo o processo. Perceber isto pedagogicamente é o mais importante nesta reflexão aqui tecida.

Após a constituição do que acabei por ver como uma dimensão teatral (por conta da percepção dos atuantes e das forças agindo), por instruções ver-bais e sem interromper o trabalho, fui eliminando cada vez mais regras explí-citas e arbitradas por um condutor. Nesta ordem e com intervalos de tempo, instruí que:

- não era mais necessário obedecer a ciclos; assim, eles podiam decidir quem levar sem racionalismos (aquilo que fiz bem no início, como falado anteriormente, ao perceber que isso desviava os atuantes do que eu considerava necessário investigar); 
- não era mais necessária, após um tempo, a trajetória diagonal (eles poderiam carregar a pessoa pela sala como fosse definido pelo trabalho);

- não era necessário, finalmente, haver a regra principal - carregar alguém.

De modo categórico: com a dimensão constituída, não havia mais regras explícitas ou predefinidas. As aberturas e fechamentos, decisões, recusas e aceitações, eram feitas sem comunicação ou predefinições, mas em regras e modos produzidos (inventados?) pelas relações de forças criadas por todos em relações com os fluxos destas forças.

\footnotetext{
Trata-se de inventar modos de existência, segundo regras facultativas, capazes de resistir ao poder bem como se furtar ao saber, mesmo se o saber tenta penetrá--los e o poder tenta apropriar-se deles. Mas os modos de existência ou possibilida-des de vida não cessam de se recriar, e surgem novos. (DELEUZE, 1992, p. 116.)
}

Em termos de regras e tarefas de exercício de aula, a situação era homô-noma à da aula anterior, em que surgiu inicialmente uma improvisação sem regras, sem proposta definida. Mas isso ocorreu de modo diferente, após um processo de instauração e posterior eliminação de regras explícitas. Os pro-cessos cênico-éticos em vigor atendiam a outro regime. Esta ética de cena se transpõe numa ética de pensamento, uma atenção específica. E, o que acabei por concluir, correspondia a um processo de subjetivação que produzia subje-tividade para aquela situação - “(...) a ética é um conjunto de regras facultativas que avaliam o que fazemos, o que dizemos, em função do modo de existência que isso implica." (DELEUZE, 1992, p. 125.)

Os atuantes (cada um e coletivamente) percebiam, dentro de forças teatrais, um fluxo teatral, uma dinâmica ou construção dos acontecimentos e iam, ao mesmo tempo em que se constituíam, construindo estes mesmos acontecimentos, que compunham uma dimensão teatral. Ação, reação, sujeito, objeto - nenhuma separação deste tipo fazia sentido: "Isso significa a palavra emancipação: o embaralhamento da fronteira entre os que agem e os que olham, entre indivíduos e membros de um corpo coletivo." (RANCIÈRE, 2012, p. 23.)

Ficou forte a percepção, para mim, já na primeira vez em que foi realizada esta atividade, a maneira de os atuantes perceberem (ser produzido, portanto) e ao mesmo tempo produzirem um modo de o espaço e do tempo se darem (as ações, a teatralidade do momento), uma maneira de coletivamente produzir a 
situação:

\begin{abstract}
A relação, entendida como agenciamento, é o modo de funcionamento de um plano coletivo, que surge como plano de criação, de coengendramento dos se-res. Cabe ressaltar que este plano coletivo e relacional é também o plano de pro-dução de subjetividades. Subjetividade aqui não é sinônimo de indivíduo, sujei-to ou pessoa, pois inclui sistemas pré-individuais/pré-pessoais (perceptivos, de sensibilidade, etc.) e extrapessoais ou sociais (maquínicos, econômicos, tecnológi-cos, ecológicos, etc.). Assim, os processos de subjetivação são sempre coletivos, na medida em que agenciam estratos heterogêneos do ser. (KASTRUP, 2005b, p. 303.)
\end{abstract}

Apesar do que chamei de "ética de cena", esta forma de pensamento não parecia considerar a produção de signos para uma plateia, mas a produção de uma situação específica, de um acontecimento que se dava no território de uma intensividade teatral (CARNEIRO, 2018, p. 278) (MAGELA, 2018, p. 305). O que importava era a interação, os agenciamentos ali produzidos. Ao mesmo tempo, este termo "forças" e a percepção de forças em relação a forças remetem ao poder, como proposto por Foucault e retomado por Deleuze em suas considerações sobre a subjetivação: "A subjetivação tem pouco a ver com um sujeito. Trata-se antes de um campo elétrico ou magnético, uma individuação operando por intensidades (tanto baixas como altas), campos individuados e não pessoas ou identidades." (DELEUZE, 1992, p. 116.)

As ações se davam como campo estético, como composição artística. Os atuantes eram o que faziam, eram aquilo que os afetava teatralmente: "segundo a maneira de dobrar a linha de força, trata-se da constituição de modos de exis-tência, ou da invenção de possibilidades de vida que também dizem respeito à morte, a nossas relações com a morte: não a existência como sujeito, mas como obra de arte.”(DELEUZE, 1992, p. 116.)

Enfocando o aspecto político destas questões, a autonomia e produção singular de subjetividade encontram um chão para vicejar, pelo trabalho de constituição de um campo de reverberação de criação de outros modos de vida, questionando e tentando minar os dispositivos que colaboram para que os modos hegemônicos de viver, baseados no sujeito e no individualismo, sejam perpetuados e não permitam que outros possam surgir:

Um outro tipo de experiência que a subjetividade faz de seu entorno é a que designo como "fora-do-sujeito", é a experiência das forças que agitam o mundo enquanto corpo vivo e que produzem efeitos em nosso corpo em sua condição de vivente. Tais efeitos consistem em outra maneira de ver e de sentir aquilo que acontece em cada momento (o que Gilles Deleuze e Félix Guattari denominaram, respectivamente, "perceptos" e "afec-tos"). Somos tomados por um estado que não tem nem imagem, nem palavra, nem gesto 
que lhe correspondam e que, no entanto, é real e apreensível por este modo de cognição que denomino "saber-do-corpo". Aqui já não se trata da experiência de um indivíduo, tampouco existe a distinção entre sujeito e objeto, pois o mundo "vive" em nosso corpo sob o modo de "afectos" e "perceptos" e faz parte de sua/nossa composição em processo. Estes formam uma espécie de germe de mundo que passa a nos habitar e que nos cau-sa estranhamento por ser, por princípio, intraduzível na cartografia cultural vigente, já que é exatamente o que lhe escapa e a coloca em risco de dissolução. (ROLNIK, 2016.)

O que mais uma vez friso como também importante aqui é que, uma vez que eles faziam isto numa percepção e num processo de decisão que escapava ao hegemonicamente comunicacional e ao racional, eles também desmanchavam convenções prévias de acordos e comportamentos, reconfigurando esse estrato da intersubjetividade. Eles estavam modulando o tempo e espaço, num comportamento específico, com invenção "em situação", in situ, compondo um território grupalmente - agenciando, portanto.

Considerei que havia ocorrido ali uma cognição teatral na melhor acepção do termo, no sentido de que suas ações eram uma percepção ativa numa dimensão teatral, nos aspectos intensivos, operativos, do teatro:

\footnotetext{
Um processo de subjetivação, isto é, uma produção de modo de existência, não pode se confundir com um sujeito, a menos que se destitua este de toda interioridade e mesmo de toda identidade. A subjetivação sequer tem a ver com a "pessoa": é uma individuação, particular ou coletiva, que caracteriza um acontecimento (uma hora do dia, um rio, um vento, uma vida...) 7. É um modo intensivo, e não um sujeito pessoal. É uma dimensão específica sem a qualnãosepoderiaultrapassarosabernemresistiraopoder.(DELEUZE,1992,p.123-124.)
}

A caracterização da situação do exercício com a produção de subjetividade, como vista por Foucault e apropriada conceitualmente por Deleuze, foi se mostrando cada vez mais consistente. Sim: as análises sobre aspectos relativos ao poder e a modos de relação com suas operações derivam dos elementos do exercício vistos à luz da elaboração conceitual. Mas estas elaborações importam-nos enquanto o fomento de modos singulares e, de certa maneira, autônomos de sermos constituídos pelo poder, lidar com ele e constituir mundos; no nosso caso, nos aspectos teatrais, aqueles situados em dimensões teatrais.

As ações que eles perpetravam, em relação aos problemas que se configuravam, assemelhavam-se às dos surfistas, em relação às ondas: “(...) surfista, aquele que nem luta desarvoradamente nem se deixa levar como um graveto, mas que tem a sabedoria paradoxal de respeitar e aproveitar a força, a veloci-dade e a intensidade das ondas." (FEITOSA, 2007, p. 29.) 
E isto diria respeito à invenção, por eles, de um pensamento (dimensão, portanto) teatral (o que ficou claro no exercício da diagonal nesse dia): inven-ção de regras, modos, outras relações de forças, que deem conta das forças em operação no aspecto teatral. O modo de apropriação e invenção de regras é que determina a singularização, bem como o estatuto dessas regras: "ainda que as práticas cognitivas configurem regras, estas são tomadas como temporárias e passíveis de reinvenção" (KASTRUP, 2005a, p. 1281). E esta invenção dentro das regras também forma uma resistência, no sentido de ultrapassar os modos do poder calcados no saber sobre um sujeito:

\footnotetext{
Não se trata mais de formas determinadas, como no saber, nem de regras coercitivas, como no poder: trata-se de regras facultativas que produzem a existência como obra de arte, regras ao mesmo tempo éticas e estéticas que constituem modos de existên-cia ou estilos de vida (mesmo o suicídio faz parte delas). (DELEUZE, 1992, p. 123.)
}

Nesse sentido, friso a ideia de que no trabalho, muitas vezes, quando há método é que algo escapa. Sim, um método móvel, mas com critérios e princípios (também móveis, mas que por algum tempo são fixos, para que algum atrito ocorra). Se tudo cede, se tudo se ajusta, talvez nada de novo advenha - apenas uma impressão de movimento - pela falta de composição de novos territórios ou de devires. O fixo e a regra também provocam movimentos de saída de si.

Porque se as decisões se dão em uma forma de pensar que escape da lógica mais estruturada da comunicação (deflagrada e/ou permitida pelas instruções que restringiam trocas de olhares e gestos), isto também constitui uma desestabilização do saber:

E o momento chega quando transpomos as etapas do saber e do poder; são essas etapas que nos forçam a colocar a nova questão, não se podia colocá-las antes. A subjetivida-de não é de modo algum uma formação de saber ou uma função de poder que Fou-cault não teria visto anteriormente; a subjetivação é uma operação artista que se distin-gue do saber e do poder, e não tem lugar no interior deles. (DELEUZE, 1992, p. 141.)

\section{Paradoxo da norma}

Neste trabalho, as regras e instruções assumem um lugar central, pois servem a propostas de autonomia numa apropriação, criação e modulação de forças e regras por parte dos atuantes, o que se espera que ocorra também com as suas vidas, fora da escola. O motivo principal já foi bem exposto: a rela-ção entre poder e produção de subjetividade dentro de uma dimensão teatral. 
A proposta pedagógica aqui abordada é a transposição de um pro-cesso teatral onde o poder é experienciado corporalmente em um pensa-mento corporal teatral, de forma a criar novas relações com o intuito de exercitar uma capacidade, na vida, de lidar com dimensões teatrais, for-ças teatrais, de forma autônoma. Assim, esta centralidade da instrução, da regra, da norma, visa a abordar meticulosamente estas questões de po-der, subjetivação, aberturas e fechamentos, porosidade ativa ou seletiva.

Uma interpretação que pode ser obtida da obra de Deleuze e Guattari - e parece ser comum em algumas abordagens decorrentes dela - é a de se priorizar as linhas de fuga, as desterritorializações, a não organização. Uma atitude de-rivada poderia ser uma aversão a princípios, critérios, regras. Mas há critérios, rigores, e mesmo muitas classificações na obra de Deleuze e Guattari, e o que nela ocorre de específico quanto a estes operadores é a maneira atroz com que eles devem ser tratados, uma maneira não fixa, sem garantias, mesmo que a cau-tela seja uma exigência: "Mas se não há ordem lógica pré-formada dos devires ou das multiplicidades, há critérios, e o importante é que esses critérios não ve-nham depois, que se exerçam quando necessário, no momento certo, suficientes para nos guiar por entre os perigos.” (DELEUZE \& GUATTARI, 1997, p. 35.)

Friso, neste aspecto, a importância de se habitar o território, distintamente de algumas apropriações das obras de Deleuze e Guattari, que por vezes parecem fetichizar a desterritorialização. Como alerta Sue-ly Rolnik, a desterritorialização não se presta muito como um objetivo:

Fatal agora pode ser o fascínio que a desterritorialização exerce sobre nós: ao invés de vivê-la como uma dimensão imprescindível da criação de territórios, nós a to-mamos como uma finalidade em si mesma. E, inteiramente desprovidos de territó-rios, nos fragilizamos até desmanchar irremediavelmentes. (ROLNIK, 1994, p. 1.)

A desterritorialização é necessária porque o território não dura para sempre. E devemos operá-la quando isto ocorre. O que se escreveu sobre o Corpo sem Órgãos, no livro Mil Platôs 3 e em AntiÉdipo, contém todo um rol de procedimentos e mesmo regras sobre este complexo jogo de aberturas e fechamentos, composições e decomposições que ("podem acreditar que9") funciona. 
Mas o principal aqui é como acolher a falha, como lidar com a não garantia, com este funcionamento avariado, em que nenhuma solução é dada previamente, em que não há controle, mas cautela. E, o que se mos-tra de vital importância, a indagação necessária sobre que elementos po-dem permitir e incentivar a vida a pulsar. Por muitas vezes, esses elemen-tos são justamente aquilo que parece, no senso comum, aprisionar a vida...

Assim, numa alternativa a visões que enfatizam aquilo que esca-pa nas situações metódicas (numa aversão a elas), uma visão possível so-bre o trabalho escrito desses dois pensadores colocaria em relevo as for-mas e os rigores que justamente promovem as desterritorializações e processos de singularização, o que de certo modo sempre permeou sua obra:

\footnotetext{
Qual é a característica distintiva de sua filosofia? O que interessa, antes de tudo a De-leuze são os movimentos aberrantes. A filosofia de Deleuze se apresenta como uma fi-losofia de movimentos aberrantes ou movimentos "forçados". Ela constitue a tentativa mais rigorosa, mais desmesurada, a mais sistemática também, de repertoriar os movi-mentos aberrantes que atravessam a matéria, a vida, o pensamento, a natureza, a histó-ria das sociedades. Classificar é uma atividade essencial em Deleuze como atividade de distinção, mas também como atividade tanto educacional como sistemática. Deleuze não cessa em distinguir e classificar os movimentos aberrantes. Sua obra, e aquela co-mum com Guattari, é como a enciclopédia.10 (LAPOUJADE, 2014, INTRODUÇÃO.) 11
}

Talvez possamos provocar algo que escapa, precisamente pela utilização feroz de um método, uma regra, um procedimento - que força o surgimento de algo. Se tudo se ajusta, se não há algo fixo (pelo menos provisoriamente), uma regra de trabalho ou instrução por exemplo, não há atrito ou pontos de apoio. Tudo sem dor, sem guerra12, mas talvez sem vida... Sim, claro: o novo ocorre se estamos abertos a ele, mesmo sem provocá-lo. Entretanto, o trabalho estruturado coletivo demanda seus rigores explícitos, principalmente se for ar-tístico, se quer provocar o novo.

As literaturas sobre jogos teatrais, principalmente as diretamente escritas por Viola Spolin, sistematizam isto - jogos com regras explícitas. Os jogos e exercícios com regras são uma simulação do real, com o qual o atuante irá se

${ }_{10}$ Quel est le trait distinctif de sa philosophie ? Ce qui intéresse avant tout Deleuze, ce sont les mouvements aberrants. La phi-losophie de Deleuze se présente comme une philosophie des mouvements aberrants ou des mouvements « forcés ». Elle cons-titue la tentative la plus rigoureuse, la plus démesuré, la plus systématique aussi, de répertorier les mouvements aberrants qui traversent la matière, la vie, la pensée, la nature, l'histoire de sociétés. Classer est une activité essentielle chez Deleuze comme activité de distinction, mais aussi comme activité à la fois pédagogique et systématique. Deleuze ne cesse de distinguer et de classer des mouvements aberrants. Son œuvre, et celle commune avec Guattari, en est comme l'encyclopédie. (LAPOUJADE, 2014, INTRODUCTION.) A tradução é minha.

11 Edição Eletrônica Kindle, sem números de páginas.

12 A referência a Heráclito (“A guerra é mãe e rainha de todas as coisas”) não é gratuita. 
confrontar, ao reconhecer a realidade destas regras, acatando-as num acordo inicial e eventualmente subvertendo-as. De certo modo, inventar mundos é inventas regras (nomias). Sob certos aspectos, outros lugares de aprendizagem ou de práticas e experiências em geral, principalmente aqueles onde há um elemento plástico, também operam este confronto naquele que experimenta.

Trata-se, aqui nesta discussão pontual, de uma dinâmica complexa, da normatividade em si, da criação dinâmica de normas, implícitas na maior par-te das vezes, que permitem que ajamos coletivamente (MAGELA, 2019a). No caso desse aspecto, enfocado neste artigo, dessas aulas de teatro, as instruções--regras constituem o trabalho, o qual fomentará uma normatividade inventiva. $\mathrm{O}$ real simulado do teatro é majoritariamente a constituição de delimitações, que se mostram como gatilhos de produção de realidade. Tanto mais vitais e intensivas elas são, mais interessante e menos subsumida pela representação será esta operação de criação de realidades.

Para os participantes, na maior parte de exercícios e jogos, objetivos e finalidades não são a principal questão (o carregamento do colega se assemelhava a um trabalho de Sísifo13 ou às situações crônicas das peças de Beckett, sem progressão alguma ${ }_{14}$ ). Se uma tarefa sem fim é proposta, o sentido con vencional de tarefa também é desestabilizado... Por último, estas tarefas do exercício teatral não têm o caráter resolutório das tarefas como comumente consideradas, nem visam a praticar habilidades para haver problemas melhor solucionados. São situações estéticas de experienciação de uma atenção mais intensificada para que o atuante se afete por aquilo que surge para ele ou por ele.

O que se investiga aqui são "comos", modos de lidar com essa regra; a invenção e a singularidade que podem surgir nestes modos. $\mathrm{O}$ modo de se relacionar, a cada momento, a qualidade de inventividade e singularidade dessas formas de relação - móveis e eventualmente inapreensíveis por análises - são o que importa. Uma investigação sobre a possibilidade de que experiências com alguns exercícios teatrais possam ser modos qualificados de lidar com essas regras, forças, poderes; modos que possam ser somaticamente transbordados para a vida do aluno: um corpo mais potente para inventar pensamentos teatrais que lidem melhor com esses estratos teatrais de poder. 
Tentando colaborar com a compreensão destas colocações, lembro que as análises de Foucault sobre o poder (também acompanhadas e desenvolvidas por Deleuze) se opõem aos modelos tradicionais que propõem esquemas simples em que há de um lado aquele que detém o poder e oprime, e de outro aquele que é oprimido. Foucault propõe um "jogo de implicações recíprocas que selam uma interdependência fundamental" (REVEL, 2005, p. 198). O po-der nesta acepção é constituído por uma pluralidade de relações, "ações sobre ações": ... o poder, definido como um conjunto de ações sobre ações possíveis, implica, assim, uma transformação dos sujeitos agentes - e é esta transforma-ção, sob a forma de uma escolha de reação ou de comportamento, que Foucault designará então "resistência." (REVEL, 2005, p. 201.)

Estas tarefas e regras induzem o atuante a uma nova relação. Ela é um gatilho, um deflagrador. Como uma resistência, que ocupa o lugar das formas de relação já instituídas, minando-as pela substituição, o exercício de teatro fomenta conexões que desarticulam outras conexões anteriores (as estagna-das, desejavelmente): de um sujeito constituído pelas objetivações, um sujeito constituindo-se através de práticas regradas (GROS, 2018, p. 462).

Assim, pontos de vista que aderem à ideia de uma liberdade e plenitude do ser com ausência de regras, critérios e limites seriam estranhos à concepção aqui adotada, que se pauta pela potência e invenção de modos de vida justa-mente dentro das relações de força constituídas como poder: "Os agenciamen-tos são passionais, são composições de desejo. O desejo nada tem a ver com uma determinação natural ou espontânea, só há desejo agenciando, agenciado, maquinado.” (DELEUZE \& GUATTARI, 1997, 78.)

Neste trabalho, aproveito para esclarecer que não é defendido que seria necessário passar por regras externas ou aprender muitas regras para apenas depois agir segundo as próprias regras. Em outras palavras, que seria preciso submeter-se para apenas depois ser livre. Dentre outros motivos, uma vez que não há liberdade (no sistema de pensamento aqui adotado), não há um ape-nas depois livre. O processo de subjetivação, no seu aspecto sempre presente de "sujeição15", pode ser ao mesmo tempo produção de subjetividade inventi-va (singular). E reconhecer uma realidade (acatar consciente ou inconscientemente a existência de forças já em curso numa determinada realidade) se dá já 
construindo formas de se relacionar com ela.

Não é gratuito que um dos valores éticos mais importantes e solicitados politicamente na educação, a autonomia, seja etimologicamente agir segundo as próprias leis . Neste sentido, não há efetivas e essencialmente próprias regras, uma vez que a autonomia é sempre relativa ou virtual.

A subjetivação, que aqui é desejada inventiva, dobra as linhas do poder, coextensiva e cooperacionalmente:

\begin{abstract}
Não se deve acreditar que a subjetivação, isto é, a operação que consiste em dobrar a linha do fora, seja simplesmente uma maneira de se proteger, de se abrigar. Ao contrário, é a única maneira de enfrentar a linha e de cavalgá-la (...). (DELEUZE, 1992, p. 141.) A ideia fundamental de Foucault é a de uma dimensão da subjetividade que de-riva do poder e do saber, mas que não depende deles. (Ibidem, 2006, p. 109.)
\end{abstract}

As regras comentadas neste exercício são compostas pelos participantes, como as regras autoimpostas nas técnicas de cuidado de si, analisadas por Michel Foucault em A Hermenêutica do Sujeito (2018) - "artes da existência":

\footnotetext{
Deve-se entender, com isso, práticas refletidas e voluntárias através das quais os ho-mens não somente se fixam regras de conduta, como também procuram se transformar, modificar-se em seu ser singular e fazer de sua vida uma obra que seja portadora de certos valores estéticos e responda a certos critérios de estilo. (FOUCAULT, 2010, p. 18.)

É preciso duplicar as regras obrigatórias do o poder mediante regras fa-Eis cultativas do homem livre que gos: exerce. (...) ela o que fizeram os gre-ser dobraram a força, sem que deixasse de força. (Ibidem, p. 108.)
}

No que concerne aos processos de subjetivação, o poder consiste em "uma transformação da ação livre das pessoas ou dos grupos, e não como sua eliminação" (REVEL, 2005, p. 199). E, também importante, o modelo de repressão é desconstruído por esta noção composta por Foucault, inovadora, de que as relações de poder produzem:

Dizer que as relações de poder produzem é reconhecer que elas induzem efeitos que não são apenas de gestão, limitação e, eventualmente, de sanção do real, mas que elas permitem, ao contrário, um excedente positivo de realidade - ou , para dizer em ter-mos mais ontológicos do que políticos, uma produção de ser.16 (REVEL, 2005, p. 198.)

E a centralidade da instrução e das regras se mostrou um labora-tório de produção desta inventividade que lida com regras e inventa re- 
gras facultativas e modos de ser estéticos situados que “cavalgam o poder".

Era isto o que ocorria nessa situação cênica do exercício de (inicialmente) carregar em diagonal: eles criavam coletivamente a situação, sendo produzidos no mesmo processo de relação de forças que coproduziam, continuando sua existência na exata medida em que construíam aquele mun-do (KASTRUP, 2008, p. 101). O que antes era um exercício de carregar em diagonal virou algo sem nome, indefinível, uma situação teatral que compunha seus próprios termos, inapreensível pelo saber (pelo menos por uma duração: sabemos que tudo é capturado e que este escape é provisório17...).

Além disso, o modo coletivo de construção dos acontecimentos dissolvia a agência individual e suas decorrências, destituindo "todo sujeito em proveito de agenciamentos do tipo hecceidade, que abrigam ou liberam o acontecimen-to naquilo que ele tem de não formado, e de não efetuável por pessoas (algo lhes acontece que eles não podem restituir a não ser destituindo-se de seu poder de dizer eu" ${ }_{18}$ (DELEUZE; GUATTARI, 1997, p. 53). Este fato questionava, para olhares atentos, pontos de vista afinados com a estrita identificação do indivíduo como unidade biológica. E, a reboque disso, as situações escoradas pela primazia do sujeito convencional - uma existência baseada numa suposição do indivíduo senhor de si, com suas decorrências, como alma, vontade individual, livre arbítrio, escolha e liberdade, responsabilidade jurídica, etc.: "Não há sujeito, mas uma produção de subjetividade: a subjetividade deve ser produzida, quando chega o momento, justamente porque não há sujeito" (DELEUZE, 1992, p. 141).

\section{Arremates}

O que fica claro como orientação priorizada aqui para a educação teatral é a condução qualificada de situações em que se dê este tipo de produção teatral de subjetividade, ou processo teatral de subjetivação, expandindo a potên-cia dos praticantes de se afetarem teatralmente e produzirem outras dimensões teatrais.

Este "rizoma de atenção teatral" seria percebido-produzido pelo incre- 
mento da percepção teatral no aluno, para ele compor e habitar territórios singulares e ser disponível a desterritorializar-se quando necessário. Em complemento, poder trabalhar mais sob novos afetos, para novas composições de território. Tudo isto pode ser operado nos exercícios e na improvisação (MAGELA, 2018b), se estes são conduzidos com a atenção voltada para estas potências e elementos (com princípios que se voltem a isto).

A exposição deste exercício de carregar em diagonal visa a mostrar a co-nexão da situação de atuação teatral com a produção de subjetividade. $\mathrm{O}$ fato de ele ser "proto", minimalista, simples, só confirma que o que importa é o modo teatral intensivo das coisas se darem, e não a cena acabada ou subsumida por um "olhar de plateia" convencional. Além disso, este caráter "proto", laboratorial, "nuclear" conecta-se com uma opção de não apresentar sugestões utilitaristas que possam ser diretamente aplicadas. Porque o objetivo aqui é propor pensamentos, critérios, filosofias de trabalho que possam inspirar as práticas de docência, que sempre são singulares e em resposta a situações bem concretas.

Essa situação teatral (a relatada e todas as outras similares neste aspecto) apresenta uma "homonomia" com processos de subjetivação. Este tipo de percepção e modo de ação teatral se mostra como processo de subjetivação uma vez que nela o atuante é feito (produzido, uma vez que ele é aquilo que percebe, faz) e faz (produz, uma vez que a situação é o coletivo fazendo) em forças teatrais. Ele tem de tomar decisões em fluxo, com um pensamento corporal, sem o uso de comunicação explícita ou compreensão racional do que se passa, num "pensamento-artista": "trata-se da constituição de modos de existência ou, como dizia Nietzsche, a invenção de novas possibilidades de vida. A existência não como sujeito, mas como obra de arte" (DELEUZE, 1992, p. 120).

O que podemos perceber é que são microprocessos de subjetivação, percepções teatrais que permeiam o dia a dia, como a atenção para agir no momento oportuno; conectar minha ação com as ações já ocorrendo na situação em que entrei ou estou, mesmo sem entendê-la racionalmente; a utilização de padrões de comportamento e o abandono deles (inventando novos, eventualmente); percepção de implicações complexas do fluxo dos acontecimentos produzindo alterações nele em diferentes modos e níveis; criticar minhas ações e as de outros e imaginar situações paralelas ao mesmo tempo que ajo (e sem parar de agir, ao modo de um ator em cena); dentre outras a ser inventadas. 
Estratos teatrais na vida de todos, dimensões cuja educação, enquanto política pública, cabe a professores de teatro licenciados.

Falar que há processo de subjetivação teatral, que os alunos atuantes se subjetivam teatralmente, é dizer que o teatral pode existir consistentemente na vida, nos modos teatrais, fluxos teatrais dos acontecimentos, como tenta ilustrar a retomada de operações cognitivas do parágrafo anterior. É mostrar que o processo de subjetivação (o já abordado nas obras de Foucault, Deleuze, Guattari e outros) tem uma dimensão teatral, e que talvez ela seja uma das mais atuantes na vida cotidiana.

Expondo de outro modo, é mostrar que aulas de educação teatral realmente dizem respeito a algo constitutivo da vida de todos e que podem realizar interferências efetivas nesse sentido, pois se tocam nos modos em que os alu-nos se relacionam com estas dimensões constitutivas.

A promoção de uma produção de subjetividade teatral singular adviria da prática intensiva (em seus aspectos operativos) desta subjetivação teatral nas aulas, sendo transposta, por transbordamento somático, para a vida dos alunos. A potência para lidar com forças (poder) é praticada pela invenção, dentro de regras e compondo novas regras, de modos de existência potentes em dimensões teatrais.

É posta, então, em relevo, a importância de uma educação dirigida à per-cepção e consideração da realidade dos processos teatrais que estão na vida de todos, e a prática de modos de habitar estes fluxos, compondo-os também. E promover, sim, um aumento da habilidade do aluno com estas operações de perceber os fluxos e dimensões teatrais da realidade, lidar com eles e produzi--los coletivamente (e de maneira singular). Em outras palavras, uma transpo-sição da ampliação de potência teatral, fomentada dentro da aula, para a sua vida. 


\section{Referências}

ANDRÉ, Carminda Mendes. Espaço inventado: o teatro pósdramá-tico na escola. Educação em Revista, Belo Horizonte, n. 48. Disponível em <http://www.scielo.br/pdf/edur/n48/a07n48.pdf>.

BORDEAUX, Marie-Christine. L'évaluation des "effets " de l'éducation artistique et culturelle. Étude méthodologique et épistémologique. Rapport final. Laboratoire Éducation Culture Politiques. Université Lyon2, Université Grenoble Alpes, 2016. Disponível em <https://re-cherche.univ-lyon2.fr/ecp/ressources/axe3/levaluation-des-effets-de--12019education-artistique-et-culturelleetude-methodologique-et--epistemologique/view>.

BOURDIEU, Pierre. A ilusão biográfica. In: FERREIRA, M. D. M., AMADO, J (org). Usos e abusos da história oral. Rio de Janeiro: Edito-ra FGV, 2006.

CARNEIRO, Gabriel José. Princípios e práticas em educação teatral: aulas de teatro com pré-adolescentes no CAIS Santa Cruz de Minas. Rascunhos - Caminhos da Pesquisa em Artes Cênicas, Uberlândia, v. 5, n. 3, 2018. Disponível em: <http://www.seer.ufu.br/index.php/ras-cunhos/article/view/43118>.

CHOQUET, Céline \& KERLAN, Alain. L'art au collège: quels effets pour les eleves?. 2016. Thèse de Doctorat - L'Université de Lyon 2. Disponível em: <http://theses.univlyon2.fr/documents/lyon2/2016/ choquet_c\#p=1\&a=TH.1>.

COSTA, Sylvio de Sousa Gadelha. Governamentalidade Neoliberal, Teoria do Capital Humano e Empreendedorismo. Educação e Realidade, Porto Alegre, v. 34, n. 2, 2009. Disponível em <https://seer.ufrgs. br/educacaoerealidade/article/view/8299/5537>.

DELEUZE, Gilles \& GUATTARI, Félix. Mil Platôs - Capitalismo e Es-quizofrenia, vol. 4. São Paulo: Editora 34, 1997.

DELEUZE, Gilles. Conversações: 1972 - 1990. São Paulo: Editora 34, 
1992.

Foucault. São Paulo: Brasiliense, 2006.

FEITOSA, Charles. Revolução, revolta e resistência: a sabedoria dos surfistas. In: LINS, D. (org). Nietzsche e Deleuze - Arte e Resistência. Rio de Janeiro: Forense Universitária, 2007.

FOUCAULT, Michel. Microfísica do Poder. São Paulo: Graal, 1985 (2007).

. História da sexualidade 2 - o uso dos prazeres. São Paulo:

Graal, 2010.

A hermenêutica do sujeito - Curso no Collège de France (1981-1982). São Paulo: Martins Fontes, 2018.

GADELHA, Sylvio. Biopolítica, governamentalidade e educação: in-trodução e conexões a partir de Michel Foucault. Belo Horizonte: Au-têntica, 2009.

GROS, Frédéric. Situação do curso. In: FOUCAULT, M. A hermenêu-tica do sujeito - Curso no Collège de France (1981-1982). São Paulo: Martins Fontes, 2018.

ICLE, Gilberto. Pedagogia teatral como cuidado de si. São Paulo: HUCITEC, 2010.

ICLE, Gilberto. Problemas teatrais na educação escolarizada: existem conteúdos em teatro? Urdimento - Revista de Estudos em Artes Cênicas, Santa Catarina, v. 2, n. 17, 2011. Disponível em: < http://www. revistas.udesc.br/index.php/urdimento/article/view/14145731021720 11070/9529>.

KASTRUP, Virginia. Políticas cognitivas na formação do professor e o problema do devir-mestre. Educação e Sociedade, Campinas, v. 26, n. 93, 2005. 
. O conceito de coletivo como superação da dicotomia indivíduo-sociedade. Psicologia em Estudo, Maringá, v. 10, n. 2, 2005.

A cognição contemporânea e a aprendizagem inventiva. In: KASTRUP, V., TEDESCO, S., PASSOS, E. Políticas da cognição. Porto Alegre: Sulina, 2008.

LAPOUJADE, David. Deleuze: les mouvements aberrants. Paris: Les Éditions de Minuit, 2014.

MAGELA, André L. L. Abordagem somática na educação teatral. Moringa - Artes do Espetáculo, João Pessoa, v. 8, n. 1. 2017. Disponível em: <http://www.periodicos.ufpb.br/ojs/index.php/moringa/article/view/34856>.

- Afecções, exercícios, protopedagogias teatrais. Rascunhos - Caminhos da pesquisa em artes cênicas, Uberlândia, v. 4, n .4. $2017 . \quad$ Disponível em: <http://www.seer.ufu.br/index.php/rascunhos/article/ view/38729>.

Cognição teatral e educação. Rascunhos - Caminhos da pesquisa em artes cênicas, Uberlândia, v. 5, n. 3, 2018. Disponível em: <http://www.seer.ufu.br/index.php/rascunhos/article/view/43132〉.

. Normatividade da cooperação em aulas de teatro. Urdimento - Revista de Estudos em Artes Cênicas, Santa Catarina, v. 1, n. 34, 2019. Disponível em: <http://www.revistas.udesc.br/index.php/ urdimento/article/view/1414573101342019110>.

. Exercícios prototípicos para uma educação teatral: uma pedagogia de composições, devir e agenciamentos. Repertório, Salvador, n. 32, 2019. Disponível em: <https://portalseer.ufba.br/index. php/revteatro/article/view/26519/19428>.

OCDE. L'art pour l'art? - L'impact de l'éducation artistique. Centre pour la recherche et l'innovation dans l'enseignement. Paris: 2013. Disponível em: <https://read.oecdilibrary.org/education/1-art-pour-1-art_9789264183841-fr\#page1>. 
RANCIÈRE, Jacques. Será que a arte resiste a alguma coisa? In: LINS, D. (org). Nietzsche e Deleuze - Arte e Resistência. Rio de Janeiro: Fo-rense Universitária, 2007.

. O espectador emancipado. São Paulo: Martins Fontes, 2012.

REVEL, Judith. Experiénces de la pensée - Michel Foucault. Paris: Bordas, 2005.

. Dictionnaire Foucault. Paris: Ellipses, 2008.

ROLNIK, Suely. A hora da micropolítica. [Entrevista concedida a] Aurora Fernández Polancos. Revista Humboldt Online. 2016. Disponível em: <https://www.goethe.de/ins/br/pt/kul/fok/rul/20790860. html>.

. Amor: o impossível... e uma nova suavidade. Palestra apresentada sob o título "O amor anda impossível?". PUC - São Paulo: Núcleo de Estudos da Subjetividade, 1994. Disponível em <http://www. pucsp.br/nucleodesubjetividade/Textos/SUELY/Novasuavidade.pdf>.

SANTANA, Arão Paranaguá de. Teatro e formação de professores. São Luís: EDUFMA - Editora da Universidade Federal do Maranhão, 2009. 